\title{
Assessment of Stress in Media Personnel (Old Media and New Media)
}

\author{
Dr. Niharika Gautam ${ }^{1} *$
}

\section{ABSTRACT}

The paper is aimed at studying the stress level in media personnel. The physical Stress Scale by Rekha Paliwal \& Shanu Maheshwari was used for data collection, based on which a detailed description of the analysis and interpretation of data is outlined. All statistics were calculated using the Statistical Package for Social Sciences (SPSS). Descriptive data together with, significant and non significant findings of independent $\mathrm{T}$ test have been reported. The present research work has following variables: The sample consisted of total 120 Personnel of Media who were purposively selected. 30 were Old Media Male Personnel \& 30 were Old Media Female Personnel of Old Media Category, another 30 New Media Male Personnel \& 30 New Media Female Personnel were of Old Media Category. The results obtained showed significant difference between the two comparative groups of Old Media and New Media.

\section{Keywords: Stress, Media, Media Personnel}

Media constitute the eyes of the human society, which is akin to a human being. The media personnel constitute the nerves in these eyes. The health of these nerves and eyes determines what the society sees, how it feels and the way in which it responds. Today, these eyes are exposed to enormous stress and strain due to rapidly changing, complicated and hence confusing and disturbing events in the world. What's stressful to one person may be all in a day's work for another. The difference appears to lie in our perceptions of various events. Media personnel who work in difficult situation are prone to stress than people of any other occupation. Further, it has been reported that 2007 has been a difficult year for journalists as a record number of personnel had been killed or injured while on duty. Mental health professionals believe personality plays a significant role in how we perceive stress.

Stress has become an integral part of modern work life, but it can lead to a range of physical ailments, such as heart disease, mental problems, lack of sleep and loss of resistance to illness.

\footnotetext{
${ }^{1}$ Clinical Psychologist, New Delhi, India

*Responding Author

(C) 2016, N Gautam; licensee IJIP. This is an Open Access Research distributed under the terms of the Creative Commons Attribution License (http://creativecommons.org/licenses/by/2.0), which permits unrestricted use, distribution, and reproduction in any Medium, provided the original work is properly cited.
} 


\section{Assessment of Stress in Media Personnel (Old Media and New Media)}

Radio and TV broadcasting work involves a number of potential hazards, including looming deadlines, team work, shift work, changing technology, demands on productivity, on-going competition and resource management, which necessitate proper individual and organizational stress management.

In one of the studies, self-reported overtime and sick leave seem to be associated with a higher level of self-reported stress, regardless of age, gender or work duty. Studies also show that men and women handle stress differently - a difference that some scientists attribute, in part, to estrogen. This hormonal difference may also account for the fact that women are three times more likely to develop depression in response to the stress in their lives than men. Women, unlike men, also tend to have stronger social support networks to which they turn to during times of stress. These social supports may help explain why women, in general, seem to be better able to cope with stress than men.

The concept of Stress was first coined by Hans Selye in 1936. Derived from the Latin word "stringere", stress was used to mean hardship, adversity or affliction. It was used in 18th and 19th centuries to denote force, pressure, strain or strong effort with reference to an object or person (Pestonjee, 1999).

It is important to recognize that stress is a state, not an illness, which may be experienced as a result of an exposure to a wide range of work demands and in turn can contribute to an equally wide range of outcomes, which may concern the employee's health and be an illness or an injury, or changes in his/her behavior and lifestyle. This arises from a study that showed that three quarters of executives say that stress adversely affects their health, happiness and home life as well as their performance at work.

Job stress can have a substantial negative effect on physical and emotional health. Williams and Huber (1986) provide a comprehensive list of the symptoms of stress. These are: "constant fatigue, low energy level, recurring headaches, gastrointestinal disorders, chronically bad breath, sweaty hands or feet, dizziness, high blood pressure, pounding heart, constant inner tension, inability to sleep, temper outbursts, hyperventilation, moodiness, irritability and restlessness, inability to concentrate, increased aggression, compulsive eating, chronic worrying, anxiety or apprehensiveness, inability to relax, growing feelings of inadequacy, increase in defensiveness, dependence on tranquilizers, excessive use of alcohol, and excessive smoking." Furthermore, job stress can make people more susceptible to major illnesses. High stress managers are twice as prone to heart attacks as low stress managers. (Rosenman and Friedman, 1971)

Excessive job-related stress is not a small or isolated problem. Over one-third of all American workers thought about quitting their jobs in 1990. One-third believe they will burn-out in the near future, and one-third feel that job stress is the single greatest source of stress in their lives. 


\section{Assessment of Stress in Media Personnel (Old Media and New Media)}

Nearly three-fourths of all workers feel that job stress lowers their productivity, and they experience health problems as a consequence. (Lawless, 1991, 1992) Furthermore, this is not exclusively a United States phenomena. A Japanese poll conducted by the Health and Welfare Ministry in 1988 indicated that 45 percent of workers felt stress from their jobs. (Asahi News Service, 1990)

Recent studies have found evidence of dangerous physical changes attributed to prolonged stress. One New York study reported a twenty gram increase in heart muscles of those suffering from job stress. There was a significant "thickening of the heart's left ventricle, or chamber, a condition that often precedes coronary heart disease and heart attacks." (Pieper, C., 1990) Omni magazine (March, 1991) wrote about a series of experiments with rats to examine the physiological effects of prolonged stress. The researchers found that there was actually a loss of neurons in the hippocampus section of their brains. The article concluded with a warning that there is some evidence of a similar neuron loss occurs in humans.

\section{METHODOLOGY}

\section{Objective}

To study and compare the difference between stress level among Old Media Personnel and New Media Personnel, male and female, Old Media Male \& Old Media Female, New Media Male \& New Media Female, Old Media Male \& New Media Male, Old Media Female New Media Female.

\section{Hypotheses}

There would be no significant difference between stress level among Old Media Personnel and New Media Personnel, male and female, Old Media Male \& Old Media Female, New Media Male \& New Media Female, Old Media Male \& New Media Male, Old Media Female New Media Female.

\section{Sample}

On the basis of purposive sampling the size of sample consist of total 120 media people, 60 old media personnel 60 new media personnel. Both the genders were taken as sample. The sample consists of junior and main performance artists as old media personnel who performed the acts in the cable television, and the post production team as new media personnel who work for the progress of the act performed by the performance artists.

\section{Variables}

\section{Independent Variable:}

Types of Media : Old Media Personnel (performance artists of cable TV) \& New Media Personnel (post production team). Gender : Male \& Female

Dependent Variable: Stress 


\section{Description of the test}

Dr. Rekha Paliwal and Shanu Maheshwari have prepared the Psycho-Physical Stress scale. It is suitable for personal as well as group administration, 25 statements with highest t-values were selected to be worked out on 2 point scale. The positive items are to be scored 1 and negative items as 0 .

\section{RESULT AND DISCUSSION}

Appropriate statistics were used using SPSS. In which descriptive and inferential statistics were calculated as follows:

\section{RESULTS TABLES : DESCRIPTIVE STATISTICS}

\begin{tabular}{|c|c|c|c|c|c|}
\hline Category & $\mathbf{N}$ & Mean & S.D. & S.E.M. & Mean Diff \\
\hline \multirow[t]{2}{*}{ OMP/NMP } & 60 & 18.38 & 2.585 & .334 & \multirow[t]{2}{*}{3.300} \\
\hline & 60 & 15.08 & 3.647 & .471 & \\
\hline \multirow[t]{2}{*}{ Male/Female } & 60 & 15.17 & 3.697 & .477 & \multirow[t]{2}{*}{-3.133} \\
\hline & 60 & 18.30 & 2.619 & .338 & \\
\hline \multirow[t]{2}{*}{ OMMP/OMFP } & 30 & 17.23 & 2.239 & .409 & \multirow[t]{2}{*}{-2.300} \\
\hline & 30 & 19.53 & 2.417 & .441 & \\
\hline \multirow[t]{2}{*}{ NMMP/NMFP } & 30 & 13.10 & 3.736 & .682 & \multirow[t]{2}{*}{-3.967} \\
\hline & 30 & 17.07 & 2.227 & .407 & \\
\hline \multirow[t]{2}{*}{ OMMP/NMMP } & 30 & 17.23 & 2.239 & .409 & \multirow[t]{2}{*}{4.133} \\
\hline & 30 & 3.736 & .682 & 13.10 & \\
\hline \multirow[t]{2}{*}{ OMFP/NMFP } & 30 & 19.53 & 2.417 & .441 & \multirow[t]{2}{*}{2.467} \\
\hline & 30 & 17.07 & 2.227 & .407 & \\
\hline
\end{tabular}

Table :1, Mean and SD in relation to Stress in Media Personnel

From table 1 it can be depicted that Old Media Personnel seem to be restoring high scores on stress level $(n=60$, mean=18.38, $S D=2.585)$ than New Media Personnel whose scores indicates lower level $(n=60$, mean=15.08, $S D=3.647)$. Female Media Personnel seem to be restoring high scores on stress level $(n=60$, mean=18.30, $S D=2.619)$ than Male Media Personnel whose scores indicates lower level ( $n=60$, mean=15.17, $S D=3.697)$. Old Media Female Personnel seem to be restoring high scores on stress level $(n=60$, mean=19.53, $S D=2.417)$ than Old Media Male Personnel whose scores indicates lower level $(n=60$, mean= 17.23, $S D=2.239)$. New Media Female Personnel seem to be restoring high scores on stress level $(n=60$, mean=17.07, $\mathrm{SD}=2.227)$ than New Media Male Personnel whose scores indicates lower level $(\mathrm{n}=60$, mean= 13.10, SD=3.736). Old Media Male Personnel seem to be restoring high scores on stress level ( $n=60$, mean=17.23, SD=2.239) than New Media Male Personnel whose scores indicates lower level $(n=60$, mean=13.10, SD=3.736). Old Media Female Personnel seem to be restoring high scores on stress level $(n=60$, mean=19.53, $S D=2.417)$ than New Media Female Personnel whose scores indicates lower level $(\mathrm{n}=60$, mean=17.07, $\mathrm{SD}=2.227)$. 
Assessment of Stress in Media Personnel (Old Media and New Media)

INFERENTIAL STATISTICS:

\begin{tabular}{|c|c|c|c|}
\hline Category & $\mathbf{N}$ & $\mathbf{t}$ & $\mathbf{p}$ \\
\hline \multirow{2}{*}{ OMP/NMP } & 60 & 5.719 & .000 \\
\cline { 2 - 2 } & 60 & & \\
\hline \multirow{2}{*}{ Male/Female } & 60 & -5.357 & .000 \\
\cline { 2 - 2 } & 60 & & .000 \\
\hline \multirow{2}{*}{ OMMP/OMFP } & 30 & -3.823 & .000 \\
\cline { 2 - 2 } & 30 & & .000 \\
\cline { 2 - 2 } & 30 & -4.995 & .000 \\
\hline \multirow{2}{*}{ OMMP/NMMP } & 30 & 5.198 & \\
\cline { 2 - 2 } & 30 & & \\
\hline \multirow{2}{*}{ OMFP/NMFP } & 30 & 4.110 & \\
\cline { 2 - 2 } & 30 & & \\
\hline
\end{tabular}

Table 22, Independent $\mathrm{T}$ test analysis $* \mathrm{P}<.05 * * \mathrm{P}<.01$

As depicted in table (2) Independent sample $\mathrm{T}$ tests were conducted to compare the variables (Stress) in OMP and NMP and revealed a significant difference in the scores for OMP and NMP. The significant difference on Stress level was observed as $t=5.719, \mathrm{P}<.000$

Independent sample T tests were conducted to compare the variables (Stress) in MMP and FMP and revealed a significant difference in the scores for MMP and FMP. Stress level was observed as $\mathrm{t}=-5.357, \mathrm{P}<.000$.

Independent sample $\mathrm{T}$ tests were conducted to compare the variables (Stress) in OMMP and OMFP and revealed a significant difference in the scores for OMMP and OMFP. The significant difference on Stress level was observed as $\mathrm{t}=--3.823, \mathrm{P}<.000$.

Independent sample $\mathrm{T}$ tests were conducted to compare the variables (Stress) in NMMP and NMFP and revealed a significant difference in the scores for NMMP and NMFP. The significant difference on Stress level was observed as $t=-4.995, \mathrm{P}<.000$.

Independent sample $\mathrm{T}$ tests were conducted to compare the variables (Stress) in OMMP and NMMP and revealed a significant difference in the scores for OMMP and NMMP. The significant difference Stress level $t=5.198, \mathrm{P}<.000$.

Independent sample $\mathrm{T}$ tests were conducted to compare the variables (Stress) in OMFP and NMFP and revealed a significant difference in the scores for OMFP and NMFP. The significant difference on Stress level $t=4.110, P<.000$. 


\section{CONCLUSION \& DISCUSSION}

Stress is an important psychological concept that can affect health, well-being and job performance in negative dimensions, (Mojoyinola, 1984; and Olaleye, 2002). It is regarded as a force that pushes a physical or psychological factor beyond its range of stability, producing a strain within the individual. Stress is the process by which environmental events (stressors or challenges) threaten us, how these threats are interpreted, and how they make us feel (Baum et al, 1997). Lazarus (1966), conceived stress to be a threat of anticipation of future harm, either physical or psychological events that lower an individual self-esteem. It is an affective behaviour and physical response to aversive stimuli in the environment. According to Selye (1976), stress is a state within the organism characterized by general adaptation syndrome. In other word, it is the nonspecific response of the body to the demand made upon it. It suggest excessive demands that produce disturbance of physiological, sociological and psychological systems. Stress may be acute or chronic in nature (Akinboye et al., 2002). It exists in different forms. It may be psychological, emotional, social, occupation or job related. Stress experienced by workers at work is called job stress. It may be due to a number of factors such as poor working condition, excessive work load, shift work, long hours of work, role ambiguity, role conflicts, poor relationships, with the boss, colleagues or subordinate officers, risk and danger, to mention a few. Certain responses indicate the presence of job stress in an individual, or group. It may manifest by the presence of headache, sleep disturbances, difficulty in concentration, short temper, upset stomach, job dissatisfaction and low morale (NIOSH, 1998). Other manifestations or indications of presence of job stress include muscular tensions and ache, tightness in the chest, high blood pressure, heat problems, snapping and arguing with others, aggressive or hostile behaviour, blaming others or administration for tension. The above manifestations can be clearly observed in Media Personnel, which may have negative effects on their health, personal and work behaviours. The descriptive statistics obtained results, for Stress found to be high in Media Personnel. The level of Stress is likely to be more in Old Media Personnel when compared with New Media Personnel, Female Media Personnel when compared with total Male Media Personnel, Old Media Female Personnel when compared with Old Media Male Personnel, New Media Female Personnel when compared with New Media Male Personnel, Old Media Male Personnel when compared with New Media Male Personnel, Old Media Female Personnel when compared with New Media Female Personnel. Consistently supported by, Holt (1993) found that shift work can lead to a variety of physical complaints, including sleep and gastro-intestinal problems and can also interfere with the family life. It is also in the line with the findings of Lawless (1992), reported that women suffered fifteen percent more stress related illnesses than men. They also thought about quitting their jobs more often, and reported a higher incidence of burnout. Lawless proposed that this is the result of unequal pay scales and a failure of organizations to adopt policies sensitive to family issues. As more women enter the work force, the effects on their health are becoming increasingly apparent. It may be that past differences between males and females are the result of their experience in the work force, and unrelated to gender per se. Based on the Media Personnel assessment and study, the stress is not only 


\section{Assessment of Stress in Media Personnel (Old Media and New Media)}

observed in the job but also in their personal lives like inadequate rest, publicity, popularity, walking in public, abstaining from social occasions, talking about their relationships, success of the present project or getting new flicks on the basis of the progress of the old ones. The inferential statistics results for the level of Stress indicated significance in Old Media Personnel which is found to be significant at ${ }^{* *} \mathrm{P}=.001$ level hence rejecting the Hypothesis stating that there would be no significant difference between the level of Stress among Old Media Personnel and New Media Personnel. There is also a significant difference in Female Media Personnel scores at the level of $* * \mathrm{P}=.001$ which is again rejecting Hypothesis stating that there would be no significant difference between the level of Stress among Male and Female Media Personnel. There is again a significant difference in Old Media Female Personnel is observed scores at the level of $* * \mathrm{P}=.001$ which in turn rejecting the Hypothesis stating that there would be no significant difference between level of Stress among Male and Female of Old Media Personnel. There is a significant difference in Female of New Media Personnel scores at the level of $* \mathrm{P}=.001$ hence rejecting the Hypothesis stating that there would be no significant difference between the level of Stress among Male and Female of New Media Personnel. There is a significant difference in Old Media Male Personnel scores at the level of $* * \mathrm{P}=.001$ and here also we reject the Hypothesis stating that there would be no significant difference between the level of Stress in Old Media Male Personnel and New Media Male Personnel. There is again found a significant difference in Old Media Female Personnel scores at the level of $* * \mathrm{P}=.001$ therefore, here also we reject the Hypothesis stating that there would be no significant difference between the level of Stress of Female Personnel of Old Media and New Media. Therefore, the results consistently revealed that women report higher levels of chronic and daily stressors than men (Hogan, Carlson, \& Dua, 2002; Ptacek, Smith, \& Zanas, 1992; Tamres, Janicki \& Helgeson, 2002). Using a modified version of Wheaton's chronic stress inventory, 89 L. A. Gentry et al. / Californian Journal of Health Promotion 2007, Volume 5, Issue 2, 89-102 McDonough and Walters (2001) found that women's distress scores were 23\% higher than men's. Utilizing the Life Event Stressful Success Questionnaire (LESSQ), Matud (2004) asked a sample of 1,566 women and 1,250 men between the ages of 18 and 65 for the number of major life events and changes within the previous two years. Women reported being significantly more stressed than men, even when controlling for the number of life events and changes.

\section{Acknowledgments}

The author appreciates all those who participated in the study and helped to facilitate the research process.

\section{Conflict of Interests}

The author declared no conflict of interests. 


\section{REFERENCES}

Akinboye, J. O., D. O. Akinboye and D. A. Adeyemo. (2002). Coping With Stress in Life and Work Place. Ibadan: Stirling-Horden Publishers (Nig) Ltd.

Asahi News Service. (1990). Japanese Move Quickly to Fight Job Stress. Minneapolis Star/Tribune.

Baum, A., R. J. Gatchel and D. S. Krantz. (1997). An Introduction to Health Psychology. New York: The McGraw-Hill Companies.

Hogan, J. M., Carlson, J. G., \& Dua, J. (2002). Stressors and Stress Reactions Among University Personnel. International Journal of Stress Management. 9. 289-310.

Holt, R. R. (1993). Occupational Stress, in L. Goldberger and S. Breznitz (eds.), Handbook of Stress: Theoretical and Clinical Aspects. New York: Free Press. 342-367.

Lawless, P. (1991). Employee Burnout: Amerca's Newest Epidemic. Minneapolis, MN: Northwestern National Life Employee Benefits Division.

Lawless, P. (1992). Employee Burnout: Causes and Cures. Minneapolis, MN: Northwestern National Life Employee Benefits Division.

Matud, P.M. (2004). Gender Differences in Stress and Coping Style. Personality and Individual Differences. 37. 1401-1415.

Mc Donough, P. \& Walters, V. (2001). Gender and Health: Reassessing Patterns and Explanations. Social Science and Medicine. 52. 547-559.

Mojoyinola, J. K. (1984). Occupational Stress among the Student Nurses of University College Hospital (U.C.H), Ibadan: It's Effects on their Mental Health and Well-Being. Unpublished B.Sc. Project, University of Ibadan.

NIOSH. (1998). Stress at Work: Job Stress and Health. Retrieved January 9, 2006, from http://www.cdc/ gov/noish/jobstress.html.

Olaleye, B. A. (2002). Psycho-Social Effects of Job Stress and Burn-out Syndrome among Nurses in State Owned Hospitals in Oyo State. M.S.W. Project, (Unpublished) University of Ibadan, Nigeria.

Pestonjee D. M. (1999). Stress and Coping: The Indian Experience. Indian Journal of Industrial Relations. 35(2). 249-252.

Pieper, C. (1990). Job Stress can Physically Change Your Heart, Study Finds. Minneapolis Star/Tribune.

Ptacek, J. T., Smith, R. E., \& Zanas, J. (1992). Gender, Appraisal, and Coping: A Longitudinal Analysis. Journal of Personality. 60. 477.

Rosenman, R., and Friedman, M. (1971). The central nervous system and coronary heart disease. Hospital Practice. 6.87-97.

Selye, H. (1946). The General Adaptation Syndrome and the Diseases of Adaptation. Journal of Clinical Endocrinology. 2.117-230.

Tamres, L. K., Janicki, D., \& Helgeson, V. S. (2002). Sex Differences in Coping Behavior: A Meta-Analytic Review and an Examination of Relative Coping. Personality and Social Psychology Review. 6.2- 30. 


\section{Assessment of Stress in Media Personnel (Old Media and New Media)}

Williams, J. C., and Huber, G. P. (1986). Human Behavior in Organizations. Cincinnati, OH: South-Western Publishing.

How to cite this article: N Gautam (2016), Assessment of Stress in Media Personnel (Old Media and New Media), International Journal of Indian Psychology, Volume 3, Issue 4, No. 64, ISSN 2348-5396 (e), ISSN: 2349-3429 (p), DIP: 18.01.117/20160304, ISBN: 978-1-365-325199 